\title{
Ações de apoio ao empreendedorismo e à relação universidade-empresa desenvolvidas pelo Núcleo de Inovação Tecnológica da Universidade Federal de São
}

\section{João del-Rei}

\author{
Actions to support the entrepreneurship and university-business relationship developed by \\ Technological Innovation Center of the Federal University of São João del-Rei \\ Acciones de apoyo al emprendimiento y la relación universidad-empresa desarrolladas por el \\ Centro de Innovación Tecnológica de la Universidad Federal de São João del-Rei
}

Recebido: 07/02/2022 | Revisado: 18/02/2022 | Aceito: 21/02/2022 | Publicado: 03/03/2022

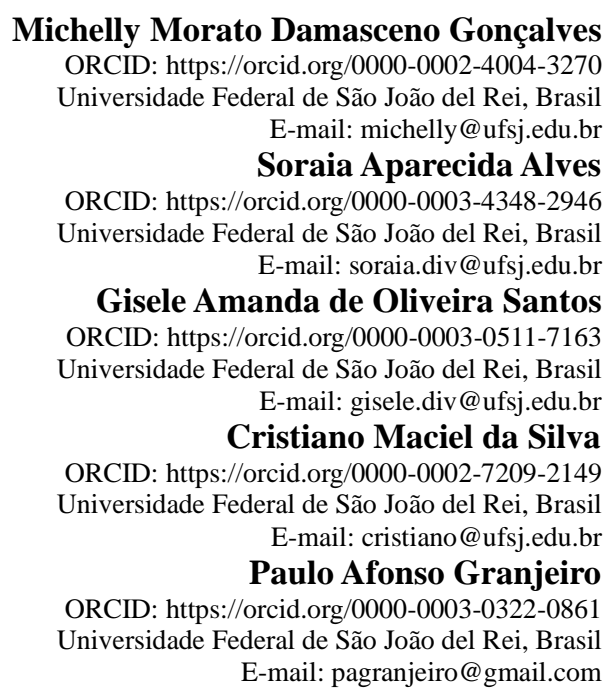

\section{Resumo}

Nas últimas décadas, o papel das Universidades vem se alterando para, além do ensino e da pesquisa, atuar como facilitadora da transferência de tecnologia e incentivadora do desenvolvimento econômico local e regional. Nesse contexto, o empreendedorismo acadêmico tem recebido atenção crescente nas áreas de ensino superior, pois passou a ser considerado um mecanismo-chave para novos avanços inovadores e desenvolvimentos econômicos regionais. Dessa forma, o presente estudo teve por objetivo investigar e discutir as ações que o Núcleo de Empreendedorismo e Inovação Tecnológica da Universidade Federal de São João del Rei tem desenvolvido para apoiar e incentivar a formação empreendedora bem como mapear os empreendimentos afiliados à universidade, na qual ele está situado. Mais especificamente foram estudadas as atividades de formação empreendedora, incubação de empresas e o mapeamento de empresas-filhas. Para alcance do objetivo geral, a pesquisa se caracteriza com uma abordagem qualitativa do tipo exploratória e utiliza a técnica de estudo de caso em uma Universidade Federal brasileira. Os resultados mostraram que, apesar de sua política de inovação estar em trajetória inicial, a Universidade estudada tem conseguido criar mecanismos de promoção ao empreendedorismo e à inovação bem como realizar uma interação Universidade-Empresa. A Universidade estudada tem alcançado resultados positivos que estão proporcionando a criação de arranjos de inovação como Startup, Spin-off, Empresas Juniores, Empresas Incubadas e Empresas-Filhas.

Palavras-chave: Empreendedorismo acadêmico; Formação empreendedora; Incubadoras de empresas; Ecossistema universitário.

\begin{abstract}
The role of universities is changing in the last decades to act as a facilitator of technology transfer and as an incentive for economic development locally and regionally. In this context, the attention on academic entrepreneurship increased in the areas of higher education once Universities are considered a key mechanism for new innovative advances. This study aimed to investigate and discuss the actions that a Center for Entrepreneurship and Technological Innovation of the Federal University of São João del Rei has developed to support and encourage entrepreneurial training and map the enterprises affiliated with the university in which it is located. More specifically,
\end{abstract}


it was investigated the entrepreneurial training activities, business incubation and the mapping of University-related companies. The present research is characterized by an exploratory qualitative approach and uses the case study technique at a Brazilian Federal University. Despite its innovation policy being on an initial trajectory, the results show that the University created the mechanisms to promote entrepreneurship and innovation, as well as to carry out the University-Company interactions. The University studied has achieved positive results that are providing the creation of innovation arrangements such as Startup, Spin-off, Junior Companies, Incubated Companies and University-related companies.

Keywords: Academic entrepreneurship; Entrepreneurial training; Business incubators; University ecosystem.

\section{Resumen}

En las últimas décadas, el papel de las Universidades ha cambiado para, además de la docencia y la investigación, actuar como facilitador de la transferencia de tecnología y promotor del desarrollo económico local y regional. En este contexto, el emprendimiento académico ha recibido una atención creciente en las áreas de educación superior, ya que ha llegado a ser considerado un mecanismo clave para nuevos avances innovadores y desarrollos económicos regionales. De esta forma, el presente estudio tuvo como objetivo investigar y discutir las acciones que el Centro de Emprendimiento e Innovación Tecnológica de la Universidad Federal de São João del Rei ha desarrollado para apoyar y fomentar la formación empresarial, así como mapear los emprendimientos afiliados a la universidad, en el que se encuentra. Más concretamente, se estudiaron las actividades de formación empresarial, la incubación de empresas y el mapeo de empresas filiales. Para alcanzar el objetivo general, la investigación se caracteriza con un enfoque cualitativo de tipo exploratorio y utiliza la técnica de estudio de caso en una Universidad Federal Brasileña. Los resultados mostraron que, a pesar de que su política de innovación se encuentra en su trayectoria inicial, la Universidad estudiada ha logrado crear mecanismos para promover el emprendimiento y la innovación, así como llevar a cabo una interacción Universidad-Empresa. La Universidad estudiada ha logrado resultados positivos que están propiciando la creación de esquemas de innovación como Startup, Spin-off, Empresas Junior, Empresas Incubadas y Empresas Hijas.

Palabras clave: Emprendimiento académico; Formación emprendedora; Viveros de empresas; Ecosistema universitario.

\section{Introdução}

Estudiosos vêm debatendo a ideia de que as Instituições de Ensino Superior (IES) são importantes meios para uma ampla gama de relações internacionais e fluxos globais contínuos de pessoas, informações, conhecimentos, tecnologias, produtos e ecossistemas empresariais (Audretsch, 2014; Guerrero et al., 2015). Dessa forma, as IES foram colocadas no centro dos ecossistemas regionais de inovação e estão sendo chamadas a contribuir para o desenvolvimento social e econômico das comunidades onde operam (Galán-Muros et al., 2017).

A literatura tem demonstrado o entendimento do porquê e como as universidades moldam a riqueza e a competitividade regional com três possíveis efeitos de causalidade, a saber, que uma universidade exogenamente promove e estimula a riqueza regional, segundo que as universidades são endogenamente moldadas pela riqueza regional e, finalmente, que a riqueza regional e as universidades seguem um caminho interligado e co-evolutivo (Lehmann \& Menter, 2016).

Nesse contexto, o empreendedorismo acadêmico tem recebido atenção crescente por parte das IES, pois passou a ser considerado um mecanismo-chave para muitos avanços inovadores e desenvolvimentos econômicos regionais (Skute, 2019).

Todavia, para que a universidade possa desenvolver o empreendedorismo acadêmico é fundamental que esta seja estruturada com recursos financeiros e humanos, bem como com normas e regulamentos internos que busquem consolidar uma política de empreendedorismo e inovação (Serviço Brasileiro de Apoio às Micro e Pequenas Empresas [SEBRAE], 2016).

Destaca-se, também, a importância da construção e da gestão de indicadores para auxiliar na tomada de decisão e na implantação de políticas adequadas aos múltiplos contextos e necessidades (Fernandes, 2004).

No caso da Universidade Federal de São João del-Rei (UFSJ), o relacionamento universidade-empresa ainda se encontra em estado embrionário. Em 2016, através da Resolução n²8/2016, a UFSJ instituiu a sua Política de Inovação. O seu Núcleo de Inovação Tecnológica (NIT) passou a ser chamado de Núcleo de Empreendedorismo e Inovação Tecnológica (NETEC) e entre suas funções está difundir a cultura empreendedora, através de atividades e programas que contribuam para a formação de empreendedores, além de estimular a atividade de incubação de empresas, através da Incubadora de 
Desenvolvimento Tecnológico e Setores Tradicionais do Campo das Vertentes (INDETEC).

No entanto, a escassez de pesquisas na área de empreendedorismo acadêmico (Tidd et al., 2005) é atribuída a fatores como o pequeno número de acadêmicos que são explicitamente conhecidos por sua universidade como estando envolvidos na atividade empresarial e a natureza tradicional das estruturas universitárias (Brennan \& McGowan, 2006).

No caso específico da UFSJ a Política de Inovação é recente e os indicadores que reflitam aspectos e situações particulares para uma adequada gestão e monitoramento do empreendedorismo e inovação são insipientes. É necessário o levantamento de indicadores como estratégia de orientar o NETEC em suas tomadas de decisão em relação às ações empreendedoras. Este estudo possibilitará a autoavaliação dos resultados e impactos dos serviços prestados pelo NETEC da UFSJ e poderá subsidiar outras instituições em suas ações de fortalecimento da relação universidade-empresa e apoio ao empreendedorismo.

Diante de tais considerações, este trabalho teve como objetivo verificar como o Núcleo de Empreendedorismo e Inovação Tecnológica da UFSJ está estruturado, mapear e discutir as ações que ele tem desenvolvido para estimular o empreendedorismo acadêmico e as relações universidade-empresa. Mais especificamente serão estudadas a estrutura do NETEC/UFSJ, as atividades de formação empreendedora por ele apoiadas, a incubação de empresas realizadas pela INDETEC e o mapeamento das empresas-filhas da UFSJ.

Este artigo encontra-se organizado da seguinte forma: Na seção 2 são apresentados os conceitos fundamentais da pesquisa. Na seção 3 é discutida a metodologia. Na seção 4 são apresentados os resultados. A seção 5 conclui o documento.

\section{Referencial Teórico}

\subsection{Universidade Empreendedora}

O termo Universidade Empreendedora está relacionado com programas de pesquisa universitários voltados para aplicações comerciais e geração de receita (Etzkowitz, 1998). Na atual sociedade do conhecimento, com a evolução do papel das Universidades, para além do ensino e da pesquisa contribuir também com o desenvolvimento econômico e social, o empreendedorismo acadêmico tem assumido um papel cada vez mais importante (Brennan \& Mcgowan, 2006).

Diante disso, estudiosos têm explorado o tema buscando esclarecer e fornecer subsídios empíricos e teóricos para que as Universidades possam ter eficácia no exercício dessa terceira função. Para Abreu e Grinevich (2013) não há, na literatura, um consenso sobre um conceito preciso de empreendedorismo. Todavia, algumas características são amplamente reconhecidas como presentes no processo de empreendedorismo, como a assunção de riscos por parte do empreendedor, o esforço de uma organização para explorar oportunidades bem como o envolvimento de atividades inovadoras.

A colaboração entre Universidades e o setor produtivo para gerar riqueza regional e competitividade é tema de muitos estudos na literatura (Lehmann 2015; Lehmann \& Menter, 2016). Essa relação tem sido demonstrada a partir da reunião de teorias e pensamentos contemporâneos, dando destaque para a importância dos transbordamentos de conhecimento das universidades para estimular a riqueza regional e a competitividade (Acs et al., 2013; Ghio et al., 2015).

Esta abordagem, a teoria do transbordamento de conhecimento do empreendedorismo, avança a base microeconômica da teoria do crescimento endógeno ao fornecer uma estrutura que explica a heterogeneidade não observada das taxas de crescimento entre regiões e nações com base em transbordamentos de conhecimento (Lehmann \& Menter, 2016).

A maioria dos estudos têm se concentrado em investigar o empreendedorismo conectado principalmente às atividades baseadas em patentes, spin-offs e licenciamento de tecnologias. No entanto, o empreendedorismo acadêmico é abrangente e envolve qualquer atividade que vá além dos papéis acadêmicos tradicionais de ensino e/ou pesquisa (Abreu \& Grinevich, 2013). 
Uma compreensão mais profunda do empreendedorismo acadêmico pode ser alcançada por meio do desenvolvimento de um modelo de processo de várias etapas que identifica os principais atores, atividades e drivers de sucesso associados a cada etapa do processo de comercialização da inovação (Wood, 2011).

Assim, o empreendedorismo acadêmico pode ser desenvolvido de diferentes formas, abrangendo uma gama de estruturas e de atividades empreendedoras (Siegel \& Wright, 2015) e funcionamento como um ecossistema. , de uma forma geral, é composto por um amplo conjunto de componentes como por exemplo, agentes do ecossistema (lideranças, gestores, empreendedores), alunos, professores, recursos para pesquisa e desenvolvimento (P\&D), escritórios de transferência de tecnologia, portfólio de tecnologias, incubadoras, formação empreendedora, Alumni, empresas estabelecidas, parceiros e fornecedores, startups, governo, etc (Lemos, 2012).

O fenômeno é compreendido como um processo dinâmico, em vez de estágios sequenciais, como um eco-ciclo organizacional, onde a ação empreendedora está ligada a fases cíclicas de gestão estratégica, conservação, crise, confusão, liderança carismática e rede criativa (Hurst, 1995).

Brennan e McGowan (2006) desenvolveram uma estrutura de análise do processo de uma Universidade Empreendedora combinando os três processos de empreendedorismo acadêmico (Busca de vantagem, busca de novidade e busca de oportunidade) com as cinco dimensões/tipos de conhecimento ontológico (Sistema empresarial, universidade, staff da Unviersidade, comunidade de prática e o indivíduo). Desta forma, os autores elaboraram um quadro que delimitou o fenômeno de uma forma diferente da tradicional visão encenada do processo de empreendedorismo para a melhor compreensão dos facilitadores e as barreiras ao empreendedorismo acadêmico.

\subsection{Formação Empreendedora}

Com o processo de globalização, o mercado de trabalho sofreu transformações e tem demandado um perfil de profissional com competências mais abrangentes e empreendedoras (no sentido amplo), que consigam trabalhar em situações cada vez mais complexas e imprevisíveis (Organisation for Economic Co-operation and Development [OECD], 2018).

Diante dessa realidade, a educação empreendedora poderia ser apontada como uma estratégia potencialmente muito eficaz (Linán, 2004), uma vez que, relatos na literatura têm demonstrado que tornar-se empreendedor pode, desde que estimulado, acontecer a qualquer pessoa (Kirby, Guerrero, \& Urbano, 2011; Dornelas, 2013;).

Um estudo empírico de Kirby e Ibrahim (2011) examinou a dominância cerebral de alguns estudantes e avaliou suas tendências empreendedoras concluindo que: quando expostas a um estilo mais empreendedor de ensino e aprendizagem, as pontuações dos alunos aumentaram cerca de $8 \%$ em um período de doze semanas, sugerindo que, se uma mudança no paradigma educacional pudesse ser efetuada, seria possível efetuar uma mudança, na maneira como os alunos pensam e se comportam, ajudando a criar uma cultura empreendedora (Kirby \& Ibrahim, 2011, p.181).

Esses resultados reforçam a ideia de que através da educação empreendedora é possível desenvolver estudantes mais empreendedores e proativos, capazes de transformar ideias em oportunidades (Wadhwani et al., 2017).

Nesse sentido, tem surgido uma infinidade de abordagens para o ensino do empreendedorismo em universidades de todo o mundo, que variam de acordo com suas intenções e objetivos (Matlay et al., 2012). Apesar do número crescente de atividades e cursos, ainda há muita discussão sobre o escopo, objetivos e metodologias que devem ser abordadas na educação para o empreendedorismo (Kuckertz, 2013; Fayolle, 2018;).

Sobretudo, estudos apontam para a importância de além de ensinar "sobre" o empreendedorismo, para que os alunos compreendam o fenômeno, deve-se ensinar "para" o empreendedorismo e prepará-los para uma atividade empresarial genuína (Matlay et al., 2012). 
Diante dessas considerações, sugere-se que o tema seja trabalhado em sala de aula, mas que também possa ser oferecida ao aluno a experimentação como importante estratégia de apoio à formação e à futura inserção no mercado de trabalho (Campos et al., 2014). Nesse contexto, existe um amplo conjunto de atividades extracurriculares que são relevantes como as atividades de Empresas Juniores (EJ), as Incubadoras de Empresas, e os Eventos Empreendedores que conectam o aluno ao ecossistema empreendedor, como rodas de conversas com empreendedores, competições de Pitch ou competições de planos de negócios, feiras de empreendedorismo, etc. (SEBRAE, 2016).

No Brasil, segundo Aranha e Garcia (2014) as universidades vêm disseminando o empreendedorismo na graduação, pós-graduação, pesquisa e programas de extensão. No entanto, de acordo com a pesquisa Serviço Brasileiro de Apoio às Micro e Pequenas Empresas [SEBRAE (2016)] sobre o empreendedorismo nas Universidades Brasileiras, as universidades não possuem uma estrutura que apoia a jornada completa do empreendedor que vai da ideia à implementação.

Os dados da pesquisa mostraram que as disciplinas curriculares são ofertadas em poucos cursos e limitadas do ponto de vista do conteúdo, motivando o aluno a dar o primeiro passo, mas, sendo insuficiente no acompanhamento do empreendimento. Além disso, poucas universidades oferecem iniciativas de eventos de empreendedorismo.

Parte deste problema é atribuído à falta de institucionalização dos programas de empreendedorismo. Segundo a pesquisa, muitas vezes, programas excelentes começam por meio da proatividade de um professor ou grupo de alunos e são interrompidos caso algum desses fundadores se aposentem ou se formem.

\subsection{Incubadoras}

As incubadoras de empresas podem ser consideradas como precursoras dos mecanismos de apoio ao empreendedorismo frente às adversidades econômicas, e sua origem remonta a meados do século XX (Associação Nacional de Entidades Promotoras de Empreendimentos Inovadores [ANPROTEC], 2019).

A literatura demonstra que as incubadoras de empresas surgiram nos Estados Unidos na década de 50, como alternativa de apoio às pequenas empresas e contribuíram para a formação de um dos maiores ecossistemas de inovação naquele país (Bizzotto et al., 2019).

No Brasil, porém, a história é mais recente tendo sido criada na década de 80 por iniciativa do Conselho Nacional de Desenvolvimento Científico e Tecnológico (CNPq) através do Programa de Implantação de Parques de Tecnologia, que apoiou projetos em diferentes regiões do Brasil (Bizzotto et al., 2019). Essa iniciativa pioneira, apoiada por políticas públicas de empreendedorismo e inovação propiciou o surgimento e consolidação do sistema de incubação de empresas e parques tecnológicos do Brasil (ANPROTEC, 2012).

O ápice do crescimento e consolidação das incubadoras de empresas em nosso país se deu a partir de 1998, quando o Ministério da Ciência, Tecnologia e Inovação (MCTIC) iniciou um projeto de estímulo às incubadoras de empresas, que culminou no desenvolvimento e criação do "Programa Nacional de Apoio às Incubadoras de Empresas - PNI" (ANPROTEC, 2019).

As definições de incubadoras de empresas estão diretamente relacionadas ao seu papel principal e apesar de não haver um consenso para uma definição única, as principais, se assemelham. As incubadoras de empresas são consideradas, de um modo geral, instituições que oferecem suporte e apoio logístico, gerencial, técnico e tecnológico aos empreendimentos emergentes, auxiliando os empreendedores no desenvolvimento inicial de suas ideias com aplicação intensiva do conhecimento, facilitando o processo de inovação e promovendo a interação com o mercado e com a sociedade ANPROTEC, 2021; SEBRAE, 2021;). 
Desta forma, é possível compreender que as incubadoras de empresas têm o papel de auxiliar empreendimentos inovadores em suas respectivas áreas propiciando um clima de acolhimento e colaboração, oferecendo suporte e recursos necessários para transformar ideias em negócios de sucesso (Souza, 2019).

Ao longo de sua história, as incubadoras de empresas não permaneceram estáticas em sua configuração original, mas, ao contrário estiveram em constante evolução mantendo sempre seu objetivo principal de acompanhar empreendimentos inovadores, desde seu estágio inicial até sua abertura ao mercado desenvolvendo ao longo do trajeto, habilidades e características essenciais à competitividade mercadológica (ANPROTEC, 2016).

Nesse sentido, observa-se a evolução dos processos de gestão das incubadoras que além de oferecer suporte básico às empresas incubadas deve também desenvolver uma atuação alinhada com as boas práticas de gestão nacionais e internacionais buscando a interação com os demais agentes do ecossistema local de inovação (ANPROTEC, 2016).

Esse processo evolutivo remete a quatro gerações de incubadoras (ANPROTEC 2018), como: a) primeira geração tem seu foco na oferta de infraestrutura física e tecnológica; b) segunda geração agrega a oferta de serviços que promovam o desenvolvimento dos empreendimentos; c) terceira geração busca estruturar redes de relacionamentos que ofereçam serviços complementares aos empreendimentos incubados; d) quarta geração passa a focar nos resultados da operação sobre o sistema de inovação da região.

Visando o desenvolvimento do ecossistema de inovação nacional auxiliando as incubadoras de empresas na escalada rumo a quarta geração, a Associação Nacional de Entidades Promotoras de Empreendimentos Inovadores (ANPROTEC) e o SEBRAE, trabalharam no desenvolvimento de modelo de gestão que promovesse a melhoria contínua das incubadoras e que fossem expressos em resultados positivos e crescentes nos diferentes setores de atuação (Bizzotto et al., 2019).

O Modelo CERNE (Centro de Referência para Apoio a Novos Empreendimentos) é uma plataforma pautada em tendências mundiais de gestão estratégica, que orienta um padrão de atuação da incubadora, com a utilização de processoschaves, que ao longo do tempo se reflete nos resultados dos empreendimentos a ela vinculados (ANPROTEC, 2018). Bizzotto et al. (2019) esclarecem que os processos-chaves deste modelo estão diretamente relacionados ao nível de maturidade da incubadora. Cada nível alcançado pela incubadora demonstra sua capacidade de melhorar continuamente gerando empreendimentos de sucesso que refletem diretamente na sustentabilidade e crescimento da própria incubadora (ANPROTEC, 2019).

O Modelo CERNE está estruturado em cinco princípios (Efetividade, Sustentabilidade, Inovação, Atuação em Rede e Desenvolvimento Regional) que são balizadores dos processos e práticas do modelo. E em três níveis de abrangência (Empreendimentos, Processos e Incubadora) que estão diretamente relacionados com os níveis de maturidade preconizados pelo modelo (ANPROTEC, 2018).

Com a implantação da cultura preconizada pelo Modelo CERNE é possível observar que quanto mais madura a incubadora está, maior é sua capacidade de gerar como resultado empreendimentos inovadores exitosos (ANPROTEC, 2018).

Devido à complexidade e variedade dos processos-chaves estabelecidos pelo Modelo CERNE, ele foi estruturado em quatro níveis, (CERNE 1, CERNE 2, CERNE 3, CERNE 4), de modo que os processos-chaves são cíclicos e cumulativos de um nível para outro.

\subsection{Empresas-filhas e spin-off}

É notório que as universidades podem desempenhar um papel importante como sementeiras de novos empreendimentos tecnológicos e tendo a pesquisa universitária como a base de criação de novos negócios tornou-se uma parte importante da política de inovação na maioria dos países (Wright et al., 2007). O mapeamento de empresas-filhas provenientes de universidades é um importante indicador da formação de profissionais com pensamento crítico e perfil empreendedor. 
Empresas-filhas são, predominantemente, empresas fundadas por ex-alunos e alunos de uma instituição. Entretanto, outros tipos de vínculo com a Universidade também tornam uma empresa-filha, tal como possuir vínculo empregatício vigente ou encerrado com a Universidade (docentes ou funcionários) ou as startups incubadas ou graduadas pela instituição (Unicamp, 2020; Bueno et al., 2020).

O primeiro mapeamento de empresas criadas por ex-alunos de uma instituição foi realizado em 2003, quando o professor Edward Roberts, junto com o então aluno de doutorado Charles Eesley desenvolveram uma pesquisa para explorar as atividades empreendedoras dos ex-alunos do Massachusetts Institute of Technology (MIT). Desde então, outras instituições realizaram estudos semelhantes sobre os empreendimentos de seus ex-alunos (Roberts, 2019).

No Brasil, a agência de Inovação da Universidade Estadual de Campinas (Inova Unicamp) é referência em mapeamento de empresas-filhas. A instituição iniciou seu cadastro em 2006, a partir de um reencontro de ex-alunos empreendedores, e até 2020 possuía 1038 empresas mapeadas (Unicamp, 2020).

$\mathrm{O}$ cadastro de empresas-filhas permite a criação de uma rede de empreendedorismo e proporciona um ambiente de colaboração entre a universidade e as empresas com compartilhamento de experiências e networking, programas de consultorias a startups, divulgação de oportunidades, participação em mentorias e palestras na universidade (Mori et al., 2017).

Além disso, o mapeamento das empresas-filhas de uma instituição é relevante, pois permite acompanhar o impacto para a sociedade de empresas criadas por pessoas que receberam apoio em ensino e pesquisa, especialmente no que tange a geração de renda e empregos (Inova Unicamp, 2020). É importante para ressaltar o papel que a universidade possui na sociedade e no estímulo a posturas empreendedoras (Bueno et al., 2020), além de incentivar que outros empreendedores reconheçam na universidade um possível parceiro para pesquisa e inovação (Berni et al., 2015).

Dentre os empreendimentos contemplados como empresas-filhas, merecem destaque as spin off, que são, às vezes, estritamente definidas como empresas que exploram propriedade intelectual ou invenções patenteadas geradas a partir de pesquisas universitárias (Di Gregorio \& Shane, 2003). Universidades como MIT e Stanford, nos Estados Unidos, são sementes de muitos empreendimentos com esse perfil, enquanto a maioria das instituições tem um histórico de um número muito limitado de spin-off de sucesso (Musta et al., 2008).

São inúmeras as razões por trás dessas variações e quando se tem um melhor entendimento de como as universidades promovem empreendimentos de alto crescimento torna-se valioso a formulação de políticas e infraestrutura para promover o empreendedorismo acadêmico. Além do mais, a promoção destes empreendimentos envolve muitos níveis dentro da universidade, como o cientista individual, grupo de pesquisa, departamento, universidade central, escritório de transferência de tecnologia e outra infraestrutura de suporte (Rasmussen \& Wright, 2015).

Assim, as competências empreendedoras necessárias para desenvolver um novo empreendimento estão relacionadas a três processos principais: a) a necessidade de desenvolver uma oportunidade de negócio viável (competência de desenvolvimento de oportunidade); b) a necessidade de defender indivíduos que forneçam significado e energia para o processo empreendedor (competência de defesa), e c) a necessidade de acessar os recursos necessários para desenvolver o novo empreendimento (competência aquisição de recursos). Para compreender como diferentes atores podem desempenhar diferentes papéis no desenvolvimento do empreendimento a utilização dessas três competências pode fornecer um referencial de competências empreendedoras como estrutura para análise (Rasmussen \& Wright, 2015).

Rasmussen e Wright (2015), ao utilizar o referencial de competências de empreendedorismo, demonstraram que o papel desempenhado pelos diferentes níveis universitários era dependente do tipo de competência considerada. Enquanto o acadêmico individual desempenha um papel fundamental no apoio ao desenvolvimento de todas as três competências empresariais, outros níveis podem desempenhar papéis mais ou menos importantes, dependendo da competência considerada. A gestão central da universidade e os alunos parecem desempenhar um papel mais indireto no apoio a spin-off. 


\section{Metodologia}

Esta pesquisa se apresenta com uma abordagem qualitativa do tipo exploratória e utiliza a técnica de estudo de caso em uma universidade federal pública brasileira. Para Hayter e colaboradores (2018), estudos que envolvem o empreendedorismo acadêmico devem ser investigados nos níveis, individual, organizacional e institucional. Isso se justifica, uma vez que as universidades são singulares e heterogêneas, possuem diferentes conjuntos de recursos e capacidades que dependem de suas características organizacionais e do contexto regional no qual estão inseridas (Guerrero et al., 2016). Dessa forma, para melhor compreensão do fenômeno estudado, optou-se pelo estudo de caso.

Foi realizada uma revisão narrativa de literatura, objetivando conhecer as iniciativas similares e o estado da arte no tema, identificando artigos e livros que tratam de empreendedorismo acadêmico e ecossistema empreendedor universitário. De acordo com Rother (2007) “os artigos de revisão narrativa são publicações amplas apropriadas para descrever e discutir o desenvolvimento ou o 'estado da arte' de um determinado assunto, sob ponto de vista teórico ou conceitual. Essa revisão foi realizada nas bases de dados do Google Acadêmico, Periódicos da Capes, Scielo e Scopus, no período de março a abril de 2021, usando as palavras-chave "academic entrepreneurship", "empreendedorismo acadêmico", "entrepreneurial ecosystem" AND "university", "ecossistema empreendedor" e "universidade”, “empresas-filhas", “incubadoras universitárias", “incubadoras de empresas", "Modelo CERNE”, "gestão de incubadoras" e "incubação de empresas", onde um subconjunto de artigos foi selecionado com base na avaliação de sua pertinência com esta pesquisa. A revisão sistemática de literatura destes artigos será apresentada num trabalho posterior.

Nesse sentido, para alcançar seu objetivo, este trabalho investiga e descreve a estrutura do Núcleo de Empreendedorismo e Inovação Tecnológica (NETEC). Para isso os dados foram coletados em relatórios e documentos institucionais. Para análise da Formação Empreendedora, foram obtidos dados acerca da oferta de disciplinas que tratam do tema de empreendedorismo. Para descobrir quais cursos ofertam essas disciplinas, foi feita uma análise qualitativa das ementas constantes na estrutura curricular de cada curso de graduação e de pós-graduação da Universidade estudada.

Os dados relacionados à INDETEC foram extraídos das pastas físicas da incubadora e das pastas compartilhadas virtualmente. O principal documento utilizado, trata-se de um arquivo eletrônico que contém informações acerca dos empreendimentos vinculados à incubadora e vem sendo alimentado continuamente desde a institucionalização da INDETEC. Para este estudo foram elencados 18 empreendimentos. Essa seleção se deu em função das informações disponíveis no momento da pesquisa. Dentre os empreendimentos relacionados, selecionou-se àqueles em que todas as informações da planilha estavam disponíveis para consulta. A planilha contempla informações gerenciais e operacionais acerca dos empreendimentos vinculados à incubadora, como por exemplo: nome, CNPJ, ramo de atividade, ingresso na incubadora, graduações, situação de mercado, faturamento, dentre outros.

As informações sobre as empresas-filhas da UFSJ foram obtidas através do cadastro realizado pelo NETEC. O mapeamento teve início no dia 23 de março de 2021 e, apesar de ser contínuo, para fins deste trabalho foram consideradas as empresas cadastradas até o dia 09 de abril de 2021 . O formulário de cadastro contém 23 perguntas, sendo 18 abertas e cinco fechadas. Os dados foram tabulados em planilhas eletrônicas e os gráficos gerados através do software Microsoft Excel 2019.

\section{Resultados e Discussão}

\subsection{Núcleo de Empreendedorismo e Inovação Tecnológica - NETEC}

De acordo com a pesquisa documental, o Núcleo de Inovação Tecnológica da UFSJ foi criado no ano de 2006 com o nome de Comissão de Propriedade Intelectual (COPIN). Essa comissão era responsável pela gestão da inovação tecnológica, bem como pela gestão da política de propriedade intelectual.

Em 2013, foi publicada a Resolução n 10/2013, através da qual criou-se o Núcleo de Inovação Tecnológica (NIT), 
que passou a ser formado por um Conselho Deliberativo e pelo Setor de Propriedade Intelectual (SEIPI). Em 2016, através da Resolução n²8/2016, a UFSJ instituiu sua política de Inovação Tecnológica e criou o Núcleo de Empreendedorismo e Inovação Tecnológica (NETEC).

A Figura 1 mostra a linha do tempo das resoluções para criação do Núcleo de Inovação bem como da política de inovação na UFSJ em comparação com a linha do tempo de criação das leis nacionais de inovação.

Figura 1: Linha do tempo das Resoluções de Inovação da UFSJ em relação às Leis Nacionais de Inovação.

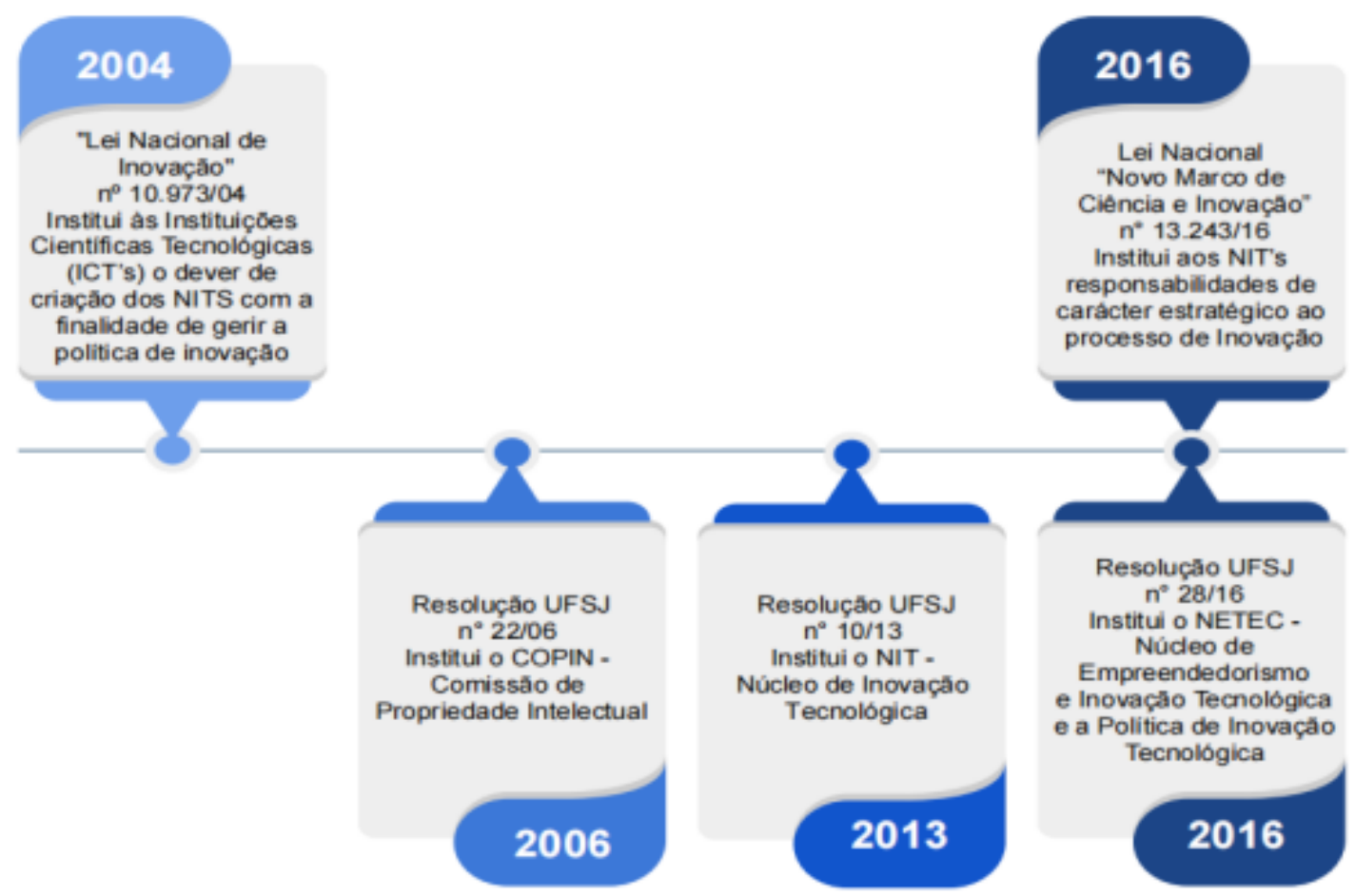

Fonte: Elaborada pelos autores com base em dados da pesquisa (2021).

Nota-se, pela linha do tempo, que tanto o Núcleo de Inovação Tecnológica quanto a Política de Inovação Tecnológica da UFSJ foram instituídos após a promulgação de leis nacionais que estipularam às Instituições Científicas Tecnológicas (ICT), nas quais se enquadram as universidades públicas, o dever de instituir os NIT para gerir a política de inovação. Esse resultado corrobora com estudos que mostram que a maior parte dos NIT brasileiros foram, formalmente, criados depois da publicação da Lei n ${ }^{10.973 / 04 ~(P a r a n h o s ~ e t ~ a l ., ~ 2018 ; ~ T e i x e i r a, ~ 2018) . ~}$

Pesquisas feitas sobre a evolução dos NIT brasileiros também mostraram que a Lei Nacional de Inovação estimulou a sua criação (Torkomian, 2009), no entanto, não se ofereceu condições para operacionalizá-lo, como por exemplo, dotá-lo de orçamento próprio (Teixeira, 2018).

Além da falta de recursos financeiros, a literatura aponta outros desafios enfrentados pelos NIT como por exemplo prover e manter o setor com recursos humanos capacitados para exercer as atividades demandadas na lei, desburocratizar processos, promover a aproximação entre Universidade-Empresa (U-E), fortalecer a cultura de inovação e empreendedorismo dentro das instituições (Ipiranga et al., 2010; Teixeira, 2018; Torkomian, 2009;). Assim, apesar da reconhecida importância que os NIT ganharam, estruturá-los ainda é uma tarefa árdua para muitas universidades públicas.

Nesse contexto, o Núcleo de Empreendedorismo e Inovação Tecnológica (NETEC) da UFSJ, bem como sua política de inovação se encontram em estágio embrionário e de estruturação. De acordo com a pesquisa documental, a composição atual do NETEC/UFSJ passou a incorporar a INDETEC (Incubadora Tecnológica de Desenvolvimento e Setores Tradicionais do Campo das Vertentes) e o SEIPI (Setor de Inovação e Propriedade Intelectual). O quadro 1 mostra a atual estrutura bem 
como os recursos humanos alocados no NETEC.

Quadro 1: Estruturação e alocação de recursos humanos do Núcleo de Empreendedorismo e Inovação Tecnológica da UFSJ.

\begin{tabular}{|c|c|c|c|}
\hline $\begin{array}{c}\text { NETEC - Núcleo de Empreendedorismo e Inovação } \\
\text { Tecnológica }\end{array}$ & $\begin{array}{c}\text { Quantidade de } \\
\text { servidores }\end{array}$ & $\begin{array}{c}\text { Quantidade de } \\
\text { Bolsistas }\end{array}$ & $\begin{array}{c}\text { Quantidade de } \\
\text { Estagiários }\end{array}$ \\
\hline Conselho Deliberativo (coordenador) & 1 & 0 & 0 \\
\hline SEIPI - Setor de Propriedade Intelectual & 1 & 1 & 0 \\
\hline $\begin{array}{c}\text { INDETEC - Incubadora de Desenvolvimento } \\
\text { Tecnológico e Setores Tradicionais do Campo das Vertentes }\end{array}$ & 1 & 4 & 2 \\
\hline
\end{tabular}

Fonte: Elaborada pelos autores com base em dados da pesquisa (2021).

Os dados revelam que a falta de recursos humanos é uma dificuldade enfrentada pelo NETEC/UFSJ. O setor conta com apenas 3 servidores efetivos, sendo que somente 2 têm dedicação integral de carga horária. Além disso, em relação ao bolsista se enfrenta o problema da rotatividade, o que dificulta a retenção de mão de obra qualificada no setor.

Essa situação, reforça os dados da Pesquisa do Fórum Nacional de Gestores de Inovação e Transferência de Tecnologia (FORTEC) realizada, em 2019, que mostra a existência de NIT sem recursos ou estruturas mínimas para o seu funcionamento adequado (FORTEC, 2020).

Os resultados indicam, portanto, que mesmo passados 15 anos da implementação da Lei de Inovação, muitas Universidades ainda não conseguiram estruturar seus NIT de forma satisfatória. Essa falta de estrutura dos NIT conduz a menos atendimentos às demandas dos pesquisadores no que se refere à propriedade intelectual e transferência de tecnologia bem como menos atendimentos aos inventores independentes e empresas do setor produtivo o que, consequentemente, implica em menos desenvolvimento econômico e social.

Apesar de todas as dificuldades e desafios, a UFSJ vem buscando aprimorar sua política de inovação e estruturar o NETEC para promover e usufruir das possibilidades que a Lei de Inovação concedeu às ICT. A figura 2 mostra que dentre as ações e arranjos de inovação existentes, na UFSJ, estão a vinculação com 21 Empresas Juniores, 5 Empresas Pré-incubadas, 1 Empresa Incubada e 35 Empresas Filhas. 
Figura 2: Arranjos de inovação vinculados à UFSJ.

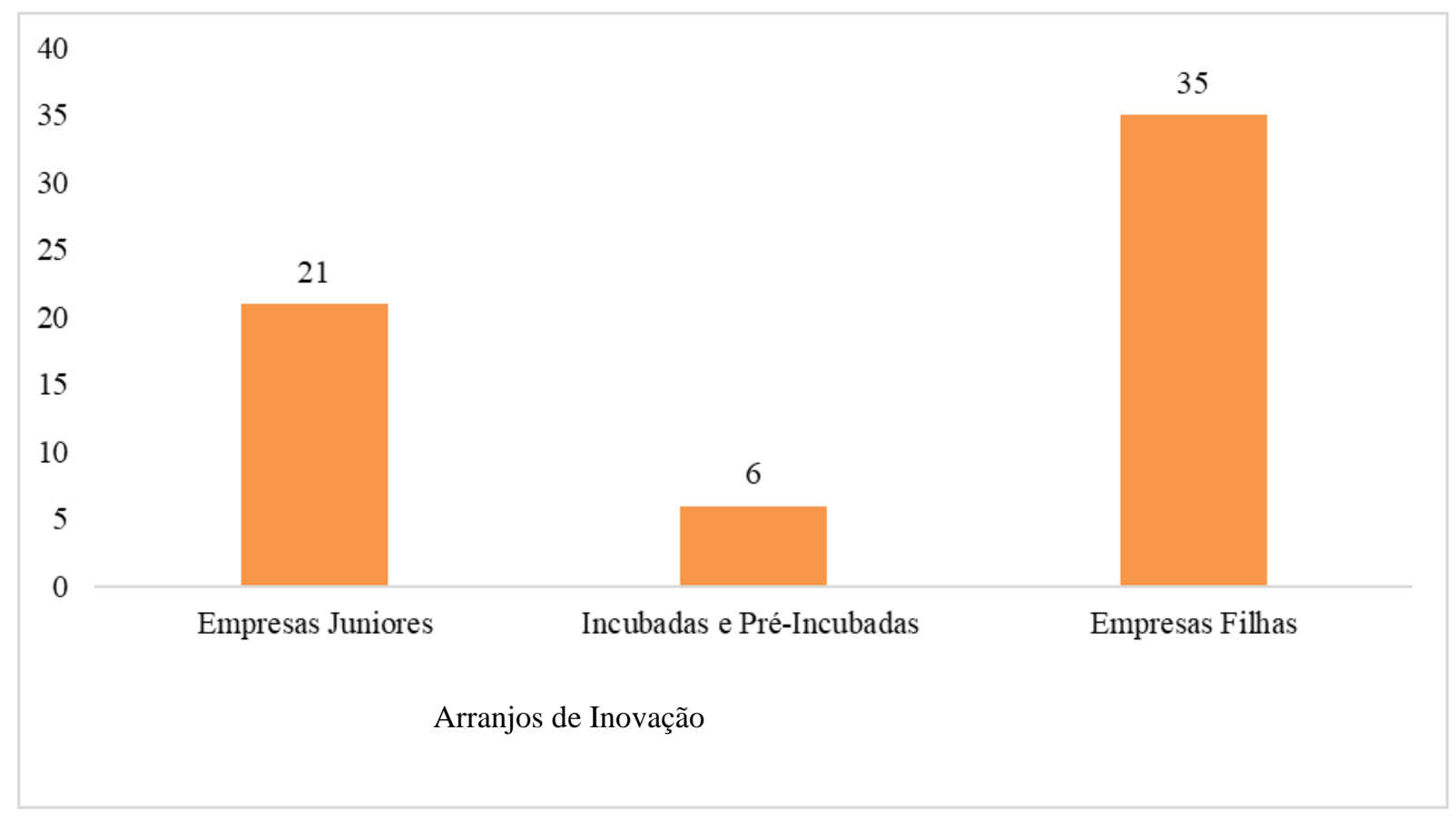

Fonte: Elaborada pelos autores com base em dados da pesquisa (2021).

Os dados mostram que, apesar de sua política de inovação estar em trajetória inicial, a UFSJ tem conseguido criar mecanismos de promoção à inovação bem como realizar uma interação U-E.

Algumas iniciativas têm alcançado resultados positivos proporcionando a criação de arranjos de inovação como Empresas Juniores, Empresas Incubadas e Empresas Filhas. Segundo Etzkowitz e Zhou (2017) esses arranjos são resultantes de um esforço intelectual inovador e são, principalmente, nesses espaços que ocorrem as atividades de inovação. $O$ mapeamento das empresas-filhas é um importante mecanismo de conexão da Universidade com os empreendedores egressos da Universidade. Mas, nota-se que será necessário uma busca ativa para a ampliação do cadastro e promover maior interação entre das empresas com o ecossistema acadêmico.

\subsection{Formação Empreendedora}

Sobre as unidades curriculares (UC) ofertadas na UFSJ, a pesquisa documental mostrou que apenas $25 \%$ dos cursos de graduação e $13 \%$ dos cursos de pós-graduação ofertam UC que abordam o tema de empreendedorismo e/ou inovação (Quadro 2).

Quadro 2 - Cursos que ofertam disciplinas sobre empreendedorismo/inovação na UFSJ.

\begin{tabular}{|l|c|c|c|}
\hline Nível & Total de Cursos & $\begin{array}{c}\text { Cursos que ofertam UC que abordam o tema } \\
\text { Empreendedorismo/Inovação }\end{array}$ & $\begin{array}{c}\% \\
11\end{array}$ \\
\hline Graduação & 43 & 4 & $13 \%$ \\
\hline Pós-Graduação & 30 & & $13 \%$ \\
\hline
\end{tabular}

Fonte: Elaborado pela autora com base em dados da pesquisa (2021).

Através da análise qualitativa das ementas dessas unidades curriculares, foi possível observar que algumas dessas UC tratam o tema apenas de maneira superficial. No entanto, também foram encontradas UC que, de maneira aplicada, estimulam 
os alunos na busca de solução de problemas e auxiliam a criação, estruturação e validação de ideias em sala de aula, utilizando metodologia Project Based (Baseado em projetos), com atividades "mão na massa", através do uso de ferramentas empreendedoras, como o canvas, mapa de empatia, canvas da proposta de valor etc.

Uma alternativa validada que o NETEC desenvolveu foi realizar uma competição de Pitch, denominada UFSJ Demoday, que reúne os times que foram criados dentro das disciplinas de Empreendedorismo. O UFSJ Demoday é um evento de fomento à inovação onde as equipes, formadas por alunos e professores, são desafiadas a apresentarem soluções inovadoras para vender uma ideia ou um negócio.

$\mathrm{O}$ evento tem uma banca formada por empreendedores, empresários e atores da sociedade, o que proporciona visibilidade à inovação e ao empreendedorismo desenvolvidos na UFSJ, além de fomentar o ecossistema local de inovação. Esse evento revelou diversas startups onde, algumas, já conseguiram apoio de pré-aceleração da Fundação Biominas, Sebrae e foram premiadas nacional e internacionalmente.

No que tange a formação empreendedora, estudos mostram que atividades curriculares e extracurriculares nas quais o estudante participa como formador de conhecimento e não apenas como receptor de informação, podem influenciar positivamente na motivação e desenvolvimento geral dos estudantes e são relevantes para o desenvolvimento de um ecossistema empreendedor (Daniel, 2016).

Nesse contexto, destaca-se a importância de a Universidade incentivar e estabelecer vínculos com Empresas Juniores, uma vez que as EJ podem promover mudanças comportamentais nos alunos, possibilitando uma melhora na empregabilidade, gerando assim um impacto econômico e social positivo (Bogo et al., 2015).

A Figura 3 demonstra que há representatividade de Empresas Juniores em cada um dos 6 campi da UFSJ, variando de 5\% (campus Centro Oeste Dona Lindu) a 29\% (campus Tancredo Neves).

Figura 3: Empresas Juniores vinculadas à UFSJ por campus de lotação.
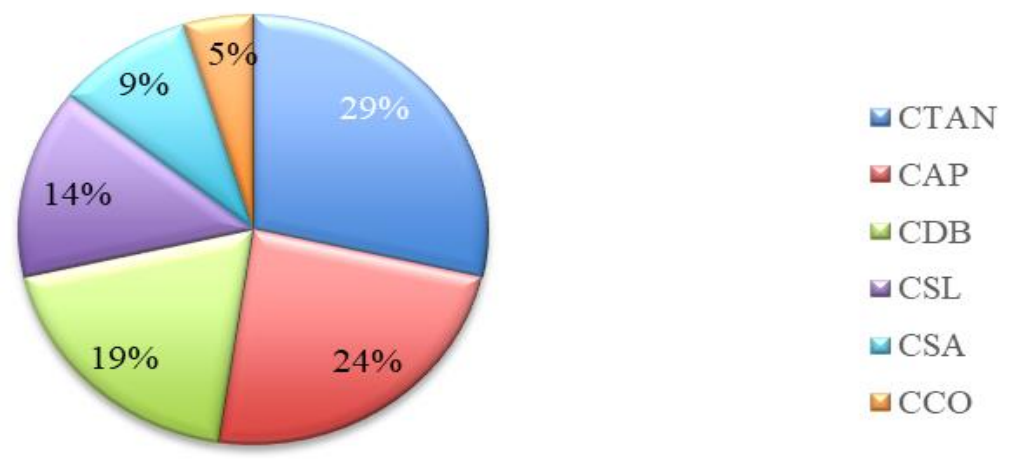

Percentual de EJ por campus de lotação

Fonte: Elaborada pelos autores com base em dados da pesquisa (2021).

A Figura 4 mostra as áreas de atuação das Empresas Juniores existentes na UFSJ, com destaque de 43\% para a área de Engenharia e de 5\% para as áreas de Biotecnologia, Ciências Biológicas, Ciências Humanas e Linguística, Letras e Artes. 
Figura 4: Empresas Juniores vinculadas à UFSJ por área de atuação.

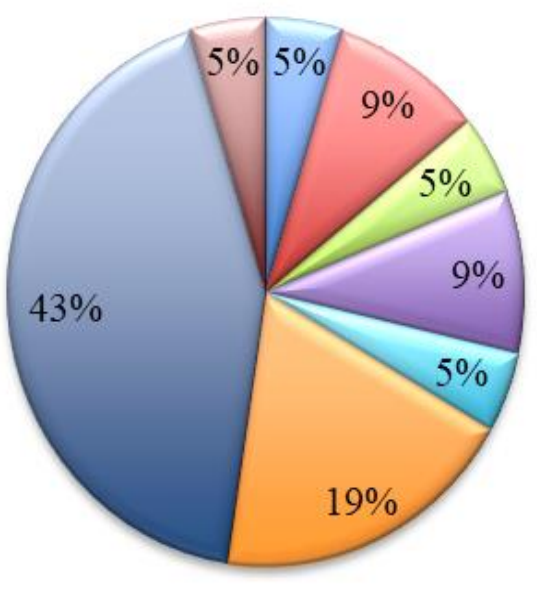

\author{
$\square$ Biotecnologia \\ $\square$ Ciências Agrárias \\ $\triangle$ Ciências Biológicas \\ $\square$ Ciências Exatas e da Terra \\ $\square$ Ciências Humanas \\ $\square$ Ciências Sociais Aplicadas \\ $\square$ Engenharias \\ $\square$ Línguística, Letras e Artes
}

Percentual de EJ por Área de Atuação

Fonte: Elaborada pelos autores com base em dados da pesquisa (2021).

Os dados mostram um maior índice de estudantes de engenharia inseridos nas Empresas Juniores (EJ). Esse resultado pode ser explicado em razão de os cursos de engenharia representarem $53 \%$ do total da oferta de vagas da UFSJ (Sistema de Seleção Unificada [SISU], 2021), mas também pode estar relacionado a estes cursos estarem mais voltados para a formação de profissionais que irão abrir empresas.

A existência de Empresas Juniores (EJ) junto à Universidade representa uma atividade empreendedora positiva para a Universidade e seus stakeholders. As EJ são consideradas espaços de crescimento e capacitação profissional uma vez que os projetos desenvolvidos proporcionam um ambiente de experimentação onde o aluno gerencia um negócio real e atua como um profissional consultor de sua área (Campos et al., 2014).

Através desses projetos os alunos têm um contato precoce com o mundo corporativo, bem como com as experiências que esses mercados oferecem (Bogo et al., 2015). Além disso, estudos empíricos mostram que as EJ têm a capacidade de fomentar o ecossistema local, uma vez que além de desenvolver comportamentos humanos e proporcionar experiências em projetos técnicos aos alunos, também se cria uma rede de contatos com empresas/empresários (Campos et al., 2014).

Considerando essa relação positiva das EJ para uma futura inserção dos alunos no mercado de trabalho, é importante que o NETEC/UFSJ promova ações para estimular outras graduações a criar e/ou ampliar o seu envolvimento com as EJ buscando a inserção de um maior número de alunos nessas atividades.

\title{
4.3 Incubadora de Desenvolvimento Tecnológico e Setores Tradicionais do Campo das Vertentes (INDETEC)
}

Criada em 2003, como um projeto de extensão da Universidade Federal de São João Del-Rei (UFSJ), a INDETEC foi institucionalizada em 2016 com a criação da Resolução 028/2016/UFSJ que criou o Núcleo de Empreendedorismo e Inovação Tecnológica da UFSJ (NETEC) e incluiu a incubadora no organograma institucional, fazendo parte deste núcleo e determinou que à INDETEC compete pré-incubar e incubar empreendimentos com probabilidade de sucesso.

A INDETEC é uma incubadora mista de segunda geração, que busca atender os setores econômicos tradicionais e estimular o desenvolvimento de novas tecnologias fomentando a cultura da inovação. A Indetec ainda não adotou a certificação pelo modelo CERNE, pois está se estruturando física e gerencialmente para atender os requisitos e obter esta importante certificação dentro dos próximos anos.

Ferreira e Teixeira (2017) apresentam as principais diferenças entre os processos de pré-incubação e incubação, 
elucidando a finalidade de cada um. Na pré-incubação a finalidade é tornar os empreendimentos aptos a fase de incubação auxiliando no desenvolvimento do plano de negócios. Sua duração é de seis a oito meses.

Na incubação a finalidade é a inserção dos empreendimentos consolidados no mercado de atuação e tem duração de dois a quatro anos. Com base na trajetória dos dezoito empreendimentos levantados para esta pesquisa observou-se que o prazo médio da pré-incubação gira em torno de 15 (quinze) meses e da incubação em torno de 28 (vinte e oito) meses.

Desta forma, é aconselhável que a INDETEC faça um estudo dos seus processos de seleção e acompanhamento de ideias insipientes, para que seja possível reduzir o prazo de pré-incubação dos empreendimentos a ela vinculados visando uma maior taxa de sucesso de seu processo de pré-incubação.

A Figura 5 demonstra que a maior parte dos empreendimentos que passaram pela INDETEC não concluíram as atividades na incubadora, o que pode ser visto como indicativo da necessidade de revisão de suas atividades e atuação junto aos empreendimentos a ela vinculados. Atualmente, dos empreendimentos ativos na incubadora uma empresa está no estágio de maturidade "incubação" e outras cinco na "pré-incubação".

Ao longo de sua trajetória, apenas duas empresas concluíram a fase de "incubação" e foram certificadas como empresas graduadas junto a INDETEC. Outros dez empreendimentos cessaram sua vinculação à incubadora durante o processo de desenvolvimento do empreendimento, sendo que os motivos relatados são diversos. Dentre esses, alguns empreendimentos não chegaram a ser validados, enquanto outros, decidiram buscar diferentes estratégias de mercado.

Figura 5: Estágio dos empreendimentos da INDETEC da UFSJ.

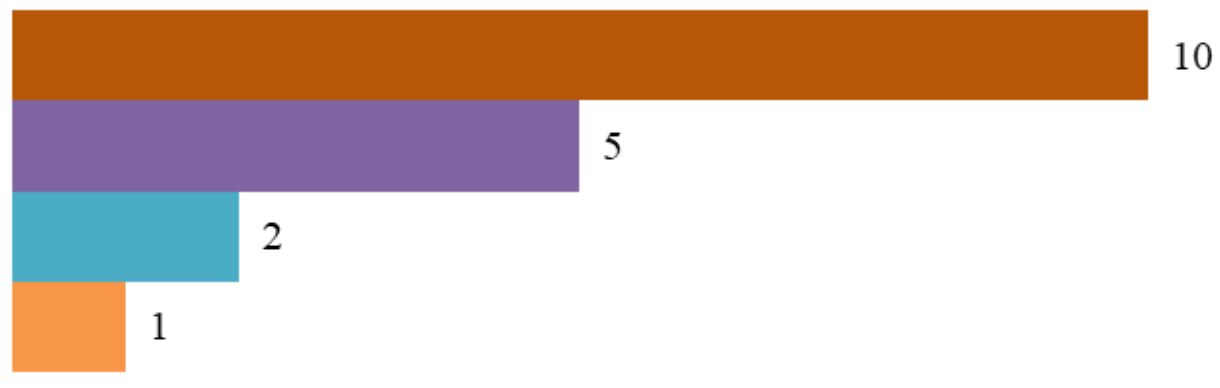

Fonte: Elaborada pelos autores com base em dados da pesquisa (2021).

Nesta pesquisa observou-se também que os empreendimentos elencados para estudo têm atuação nos três principais segmentos de mercado brasileiro (indústria, serviço e comércio), sendo que há destaque para atuação no comércio regional, com $45 \%$ dos empreendimentos apoiados.

Outra característica importante a ser apresentada neste estudo refere-se a taxa de sucesso dos empreendimentos que passaram pela INDETEC. Destes empreendimentos, quatorze estão ativos no mercado e cinco deles se tornaram empresas consolidadas e competitivas, que oferecem benefícios econômicos à região de atuação. Juntos, geram aproximadamente 70 empregos formais, diretos e indiretos, e possuem faturamento médio anual na casa dos $\mathrm{R} \$ 5$ milhões.

Esses dados corroboram com o Estudo de Impacto Econômico desenvolvido pela ANPROTEC em 2016, em que fica clara a relação entre os empreendimentos incubados e o desenvolvimento local (Anprotec, 2016).

Cumprindo seu papel de incubadora mista, a INDETEC busca atender aos setores econômicos regionais tradicionais e 
estimular o desenvolvimento intensivo de tecnologias voltadas para as demandas regionais. O grande desafio é criar a cultura de inovação nas empresas incubadas, como forma de se adaptar para evitar riscos e obter vantagens competitivas (Schaltegger 2011). Uma alternativa é desenvolver inovações orientadas (IOS) para a sustentabilidade, que são processos, produtos, estruturas organizacionais ou inovações de sistemas melhorados, com enfoque nas questões ambientais, sociais e econômicas (Hansen et al., 2009).

Com IOS pequenas e médias empresas podem conquistar nichos de mercado, reduzir o uso de recursos e melhorar a qualidade de vida. Essa tipologia contribui para o campo ainda jovem da teoria da inovação interativa (cf. Fichter 2005) ao estender a teoria da abrangência de fronteiras do contexto de intraempresa para a interação interempresarial-universidade mediada (Klewitz, 2017)

Na Figura 6 observamos como é a distribuição dos empreendimentos que passaram pela INDETEC quando relacionamos a utilização de base tecnológica.

Figura 6: Tipo de empreendimentos da INDETEC da UFSJ.

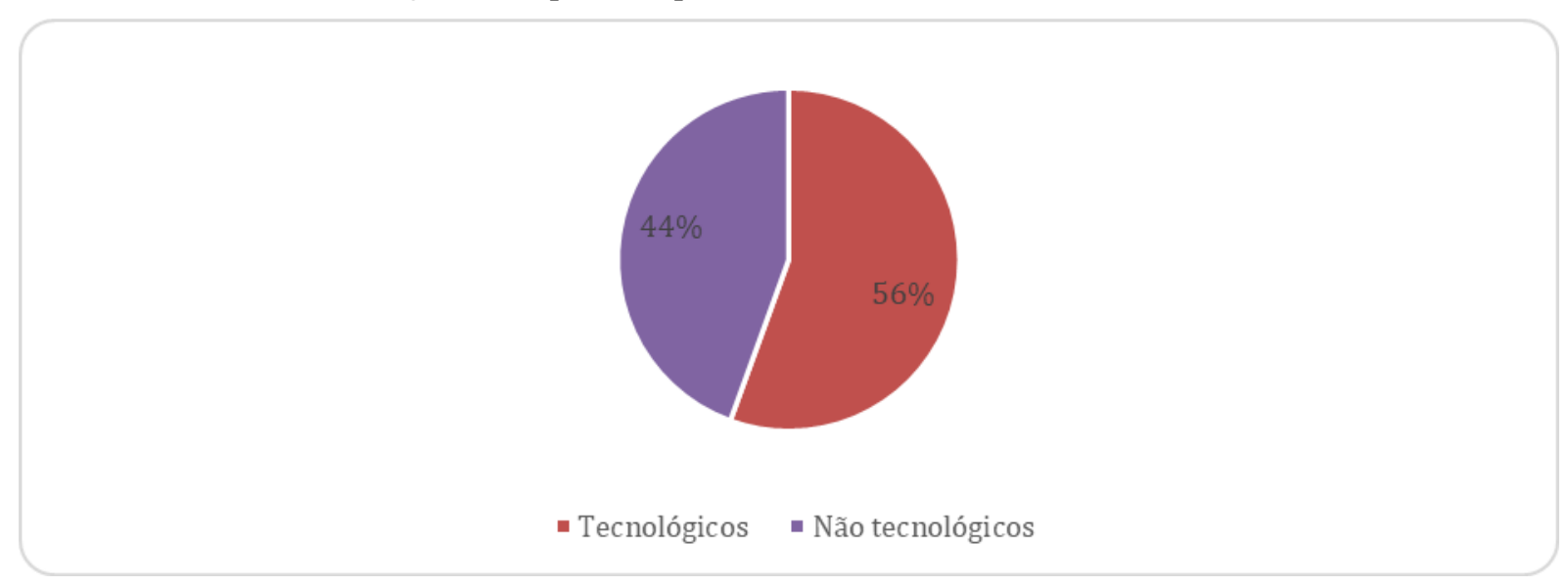

Fonte: Elaborada pelos autores com base em dados da pesquisa (2021).

Hollveg et al. (2020) salientam que as incubadoras são uma forma de fomento ao desenvolvimento de pequenas e microempresas, principalmente quando o objetivo principal é a tecnologia intensiva.

Esta tendência ao mercado empreendedor e inovador pode ser observada na atuação da INDETEC quando, apesar do equilíbrio apresentado entre os empreendimentos a ela vinculados, observa-se um maior número daqueles que desenvolvem tecnologia aplicada.

\subsection{Empresas-filhas}

A Universidade Federal de São João del-Rei - UFSJ iniciou seu cadastramento de empresas-filhas no dia 23 de março de 2021, por iniciativa de seu Núcleo de Empreendedorismo e Inovação Tecnológica - NETEC. Até o dia 09 de abril de 2021 foram cadastradas 35 empresas-filhas, sendo 91,4\% delas ativas. O NETEC manterá o cadastro aberto de forma contínua.

A Figura 7 apresenta o status das empresas-filhas da UFSJ, onde foi possível observar que 91,4\% estão ativas e 8,6\% encontram-se fechadas. Nenhuma das empresas cadastradas respondeu estar vendida ou em outro status. 
Figura 7: Status das empresas-filhas da UFSJ.

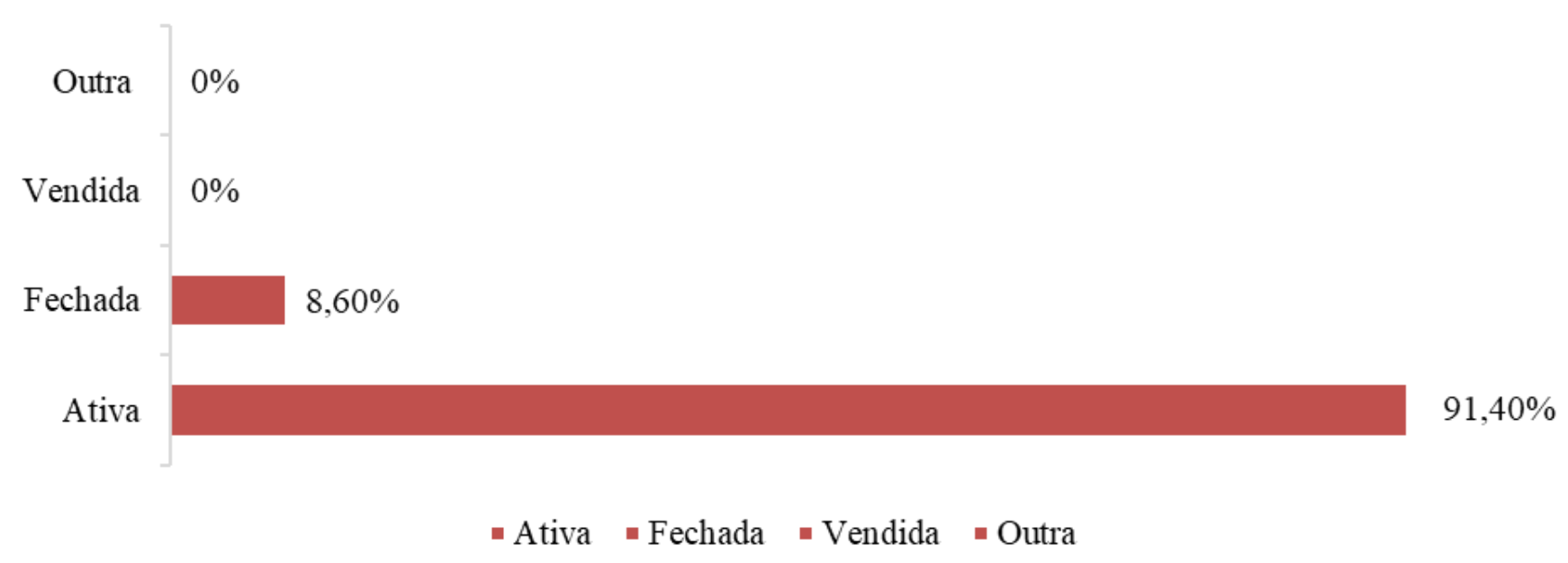

Fonte: Elaborada pelos autores com base em dados da pesquisa (2021).

Em um comparativo com outras instituições que já realizaram o mapeamento de suas empresas-filhas, verificamos que o processo de cadastro é gradual. Um exemplo é o da UNICAMP, que é referência nacional no cadastro e relacionamento com suas empresas-filhas. Em 2006 a UNICAMP possuía 130 empresas-filhas cadastradas.

O primeiro dado constando a porcentagem de empresas ativas foi divulgado em 2013, onde haviam 266 empresas cadastradas, sendo 194 delas ativas, ou seja, 73\% encontravam-se em atividade (Inova Unicamp, 2020). De acordo com o Relatório Anual de Empresas-Filhas da UNICAMP (2020) a instituição possuía até setembro de 2020, 1.038 empresas cadastradas, sendo 929 delas ativas. Houve um aumento de 908 empresas cadastradas, no período de 14 anos.

A UNESP apresentou em seu Relatório de Empresas-filhas (2020) o cadastro de 307 empresas. O cadastro de empresas-filhas da instituição foi iniciado em 2006, obtendo 170 registros de empresas neste primeiro momento.

O período de coleta considerado nesta pesquisa foi de apenas 18 dias e a expectativa com base nos cadastros realizados por outras instituições é de que o número de empresas-filhas cadastradas pela UFSJ aumente consideravelmente nos próximos anos.

A Figura 8 demonstra os empregos gerados pelas empresas-filhas da UFSJ. Foram apontados um número total de 161 colaboradores nas 35 empresas cadastradas. Juntas as empresas possuem um total de 68 sócios, sendo 55 deles com algum vínculo com a UFSJ. Dentre os vínculos apresentados $88,5 \%$ pertencem a alunos e ex-alunos e 11,5\% pertencem a professores da instituição. 
Figura 8: Empregos gerados pelas empresas-filhas da UFSJ.

\section{Numero de sócios com vínculo UFSJ}

\author{
Numero de sócios \\ Número de colaboradores
}

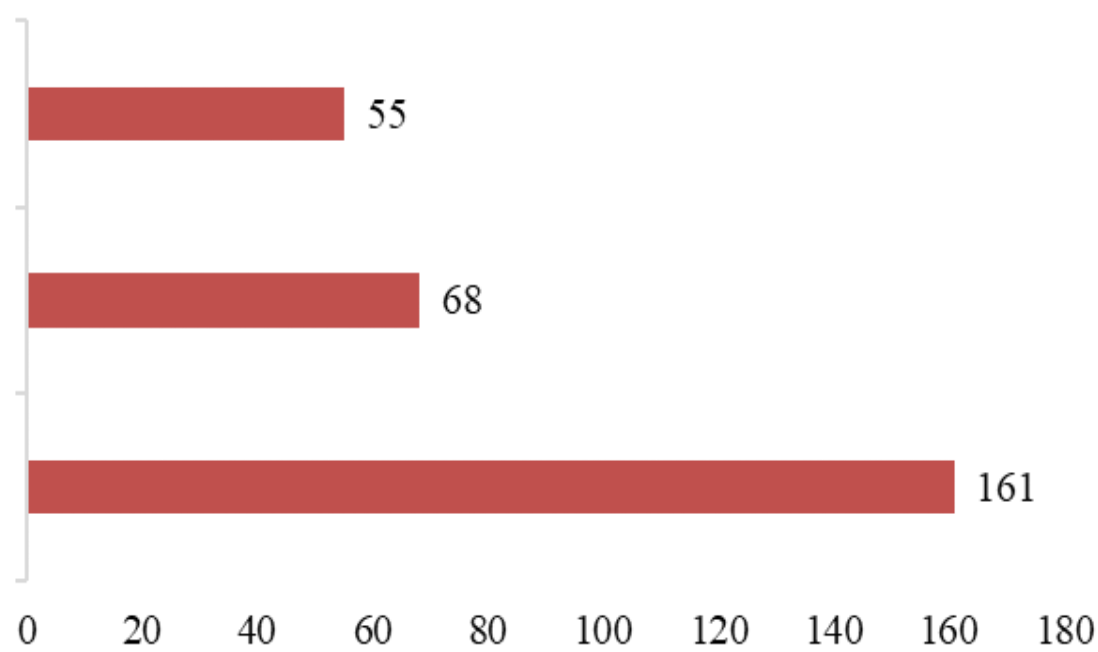

Fonte: Elaborada pelos autores com base em dados da pesquisa (2021).

As universidades são consideradas na literatura como um importante ator no desenvolvimento econômico das regiões em que estão inseridas por terem como função formar mão-de-obra especializada, ser fonte de conhecimento científico e por promover mecanismos de apoio ao empreendedorismo inovador (Etzkowitz \& Klofsten, 2005; Asheim et al., 2011; Noveli \& Segatto, 2012; Etzkowitz \& Zhou, 2017).

Segundo o Diretor-Executivo da INOVA UNICAMP um dos principais dados apurados pelo mapeamento das empresas-filhas é acompanhar o impacto da Universidade junto à sociedade, especialmente no que tange ao faturamento e geração de empregos (Inova Unicamp, 2020).

Os nossos resultados demonstram a importância de se fazer uma busca ativa para mapeamento das empresas-filhas, uma vez que outras Universidades tem avançado em um número considerável de empresas cadastradas.

O Relatório Anual de Empresas-Filhas (2020) da UNICAMP apresentou que em 2020 as empresas-filhas da instituição foram responsáveis por 33.315 empregos diretos. Barreto, Oliveira Pantaleão, Silva, \& Hirata (2019) apontaram que as 27 empresas-filhas da Universidade Federal de Mato Grosso mapeadas, geraram 569 empregos diretos. Enquanto as empresas-filhas da UNESP criaram cerca de 10.000 empregos (Bueno et al., 2020).

O número de empregos gerados pelas empresas-filhas da UFSJ é baixo quando comparado com as demais instituições apresentadas, mas isso pode estar relacionado com o fato de a UFSJ ter iniciado recentemente o seu cadastramento e ser uma IES recém-criada em comparação com as outras.

Fazendo uma proporção do número de empregos criados pelo número de empresas, as empresas-filhas da UFSJ apresentam 4,6 empregos por empresa. Ampliar as políticas institucionais de incentivo ao empreendedorismo e inovação, através de programas que estimulem a cultura empreendedora podem ajudar no crescimento das empresas existentes e na criação de novas empresas pela comunidade acadêmica, fortalecendo o Ecossistema em que a universidade está inserida. (Inova Unicamp, 2020).

A Figura 9 demonstra o porte das empresas-filhas da UFSJ. A predominância é de Microempresas (66\%), sendo seguido por empresas sem porte definido, por não ter ainda faturamento (23\%) e Pequenas Empresas (11\%). Não foram recebidos cadastros de Grandes e Médias Empresas. 
Figura 9: Porte das empresas-filhas da UFSJ.

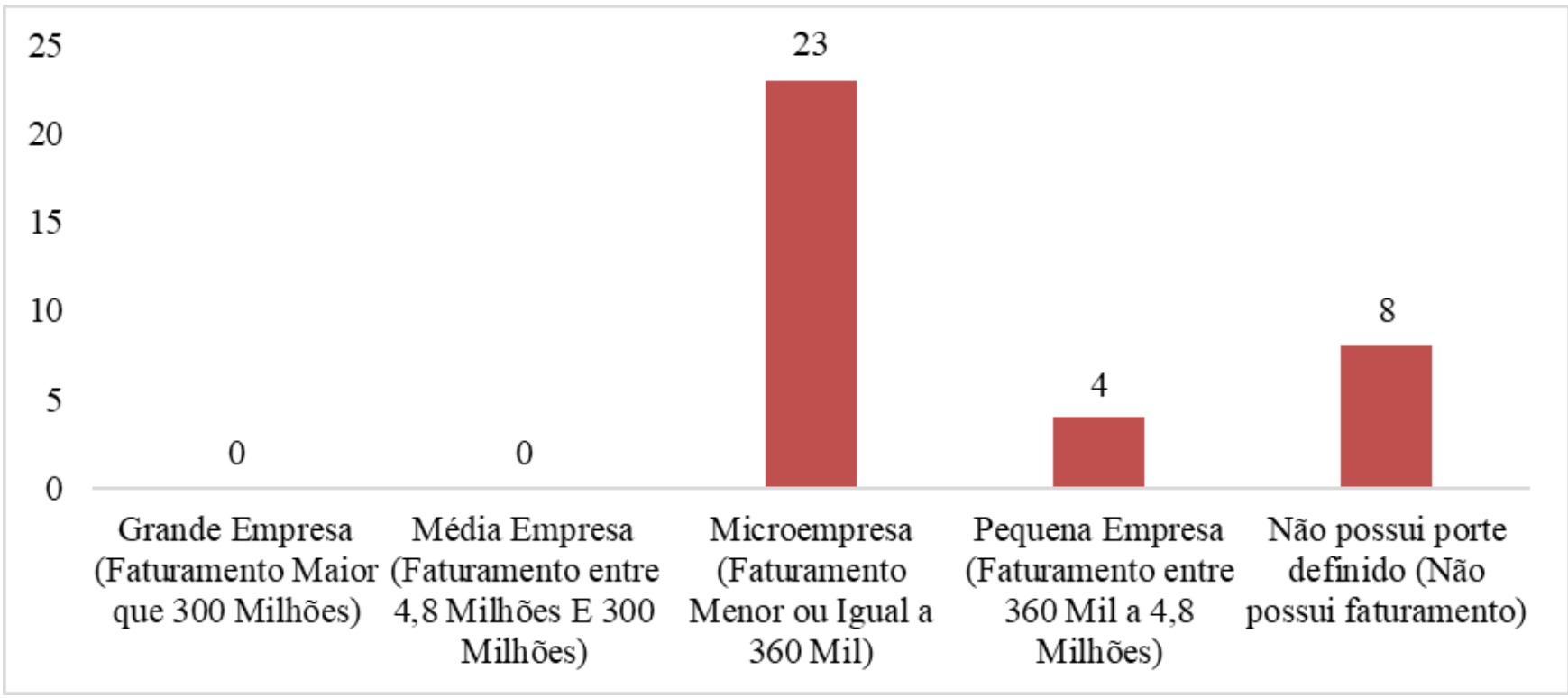

Fonte: Elaborada pelos autores com base em dados da pesquisa (2021).

O porte das empresas é indicado por faixas de faturamento, seguindo a metodologia do Banco Nacional de Desenvolvimento Econômico e Social (BNDES), sendo de zero a 360 mil reais - microempresa, de 360 mil a 4,8 milhões de reais - pequena empresa, de 4,8 milhões a 300 milhões - média empresa e acima de $\mathrm{R} \$ 300$ milhões - grande empresa) (BNDS, 2021).

Os dados de porte de empresas-filhas da UFSJ estão de acordo com o encontrado na literatura. O número de micro e pequenas empresas é predominante também entre as empresas-filhas de outras instituições que realizaram este levantamento. Na Universidade Federal do Mato Grosso (UFMT) 53,8\% de suas empresas-filhas são microempresas e 23,1\% são pequenas empresas (Barreto et al., 2019). O mesmo ocorre na UNICAMP, onde 57,3\% das empresas-filhas são microempresas e $23 \%$ são pequenas empresas (Inova Unicamp, 2020). Na UNESP cerca de 70\% são microempresas e 20\% são pequenas empresas (Bueno et al., 2020).

Bueno et al. (2020) destacam que a alta representatividade das micro e pequenas empresas apontam a necessidade de se reconhecer e valorizar o impacto desses empreendimentos no desenvolvimento local e na geração de oportunidades, e, também, a necessidade que eles possuem de estudos, estímulos, programas e parcerias que os beneficiem.

A iniciativa do NETEC/UFSJ de buscar uma articulação sistêmica entre as empresas-filhas da instituição é uma forma de a universidade cumprir esse papel de formar novos empreendedores e incentivar, através de parcerias, a criação de novos conhecimentos e produtos que promovam a instalação e crescimento dessas empresas.

Dentre as empresa-filhas da UFSJ, 23\% declararam ser uma spin-off acadêmica, apesar de ainda não terem CNPJ, mas são empreendimentos que estão passando por programas de pré-aceleração de startups e adquirindo maturidade para o mercado.

Para ocorrer a transferências de inovações detidas pela universidade para parceiros da indústria alguns mecanismos podem ser utilizados (Link et al., 2006). Destacam-se os mecanismos formas mais comuns utilizados pelas universidades para a transferência de tecnologia, como o licenciamento de tecnologia ou o lançamento de um negócio novo, denominado spin off (Wood, 2011). O elemento central das spin-offs acadêmicas são o conhecimento gerado em uma universidade ou instituição de ensino superior, e sua disponibilização à sociedade através de novos empreendimentos (Pavania, 2015).

As spin-offs são consideradas como um importante mecanismo de transferência de tecnologia da universidade para as 
empresas (Meoli et al., 2013) e geram desenvolvimento econômico e criação de empregos nas regiões onde estão instaladas (Criaco et al., 2014). Por comercializarem produtos e serviços com grande potencial de inovação, essas empresas afetam diretamente as condições e a qualidade de vida da sociedade onde estão inseridas (Peng, 2006).

Também é importante para as universidades incentivar a criação de spin offs pela comunidade acadêmica. A imagem de uma instituição competitiva e empreendedora contribui para parcerias com empresas e outras universidades renomadas (Bekkers, \& Freitas, 2008).

Dessa forma, a UFSJ, ainda de forma inicial, tem buscado esse papel de universidade empreendedora com iniciativas como o cadastro das empresas-filhas com o intuito de realizar conexões e parcerias que possam transformar estudos científicos em produtos e soluções que cheguem ao mercado em forma de tecnologias, beneficiando a sociedade.

\section{Conclusão}

Considera-se que o objetivo proposto neste trabalho foi alcançado uma vez que foi feito o levantamento de como o Núcleo de Empreendedorismo e Inovação Tecnológica da UFSJ está estruturado bem como o mapeamento e discussão das ações que ele tem desenvolvido para estimular o empreendedorismo acadêmico e as relações universidade-empresa.

Constatou-se que a Política de Inovação da UFSJ é recente e ainda se encontra em processo de consolidação e, por isso, as ações de apoio e fomento ao empreendedorismo e à inovação ainda é um desafio enfrentado pela instituição, assim como por outras universidades brasileiras. Vínculos colaborativos estão se formando e esforços estão sendo vertidos para que as ações do NETEC promovam uma cultura empreendedora dentro da UFSJ.

O mapeamento das empresas-filhas da instituição é uma iniciativa que demonstra a intenção de estreitar o relacionamento universidade-empresa, no entanto não basta apenas ter o cadastro destas empresas. O NETEC precisará criar ações e atividades que promovam uma relação de apoio mútuo entre as empresas cadastradas e a UFSJ, no intuito de promover a inovação e o desenvolvimento regional.

A institucionalização e manutenção da incubadora INDETEC é outra importante iniciativa de apoio ao empreendedorismo e fomento às pequenas e microempresas. Como incubadora mista, a INDETEC busca cumprir o papel de atender aos setores econômicos regionais tradicionais e estimular o desenvolvimento intensivo de tecnologias voltadas para as demandas regionais. Todavia, um dos principais desafios está na escassez dos recursos humanos e em ações pontuais, como por exemplo, na implantação do Modelo CERNE.

O tamanho da amostra foi uma limitação encontrada na pesquisa. Por se tratar de um estudo de caso de uma universidade ainda jovem e com políticas de inovação e incentivo ao empreendedorismo em estágio inicial, as amostras estudadas foram reduzidas. Dessa forma, os resultados encontrados devem ser considerados apenas para o estudo em questão.

Além disso, trata-se de uma pesquisa qualitativa, e por isso, a análise dos dados é subjetiva e aberta à interpretação. Dessa forma, os resultados podem trazer influências e tendências embasadas nas perspectivas dos autores.

Contudo, os resultados deste trabalho poderão subsidiar outras instituições em suas ações de fortalecimento da relação universidade-empresa e apoio ao empreendedorismo. Os indicadores apresentados demonstram a importância da implementação de uma política de inovação por parte das instituições, pois mesmo de forma ainda inicial, o NETEC vem buscando consolidar suas funções de promover o empreendedorismo e a inovação dentro da UFSJ.

Como sugestões de trabalhos futuros propõe-se um estudo sobre o ecossistema em que a universidade está inserida, através do mapeamento dos atores deste ecossistema. Quais empresas fazem parte do setor produtivo da região, as instituições de financiamento e as políticas públicas para fomento do empreendedorismo e inovação. 


\section{Referências}

Abreu, M., \& Grinevich, V. (2013). The nature of academic entrepreneurship in the UK: Widening the focus on entrepreneurial activities. Research Policy, $42(2), 408-422$

Acs, Z. J., Audretsch, D. B., \& Lehmann, E. E. (2013). The knowledge spillover theory of entrepreneurship. Small Business Economics, 41(4), 757-774.

Aranha, E. A., \& Garcia, N. A. P. (2014). Entrepreneurial university and the Brazilian system for the evaluation of higher education. International Business Research, 7(8), 73 .

Associação Nacional de Entidades Promotoras de Empreendimentos Inovadores. (2018). Cerne-Centro de Referência para Apoio a Novos Empreendimentos; textos. Brasília: Carlos Eduardo Negrão Bizzotto, Marcos Suassuna, Sheila Oliveira Pires, Gisa Helena Melo

Associação Nacional de Entidades Promotoras de Empreendimentos Inovadores. (2019) Mapeamento dos mecanismos de geração de Empreendimentos Inovadores no Brasil / Anprotec; textos. Brasília: ClaudiaPavani... [et.al.].

Associação Nacional de Entidades Promotoras de Empreendimentos Inovadores. Ministério da Ciência, Tecnologia e Inovação. (2012). Estudo, Análise e Proposições sobre as Incubadoras de Empresas no Brasil - relatório técnico. Brasília.

Audretsch, D. B. (2014). From the entrepreneurial university to the university for the entrepreneurial society. The Journal of Technology Transfer, 39(3), 313321 .

Asheim, B. T., Boschma, R. \& Cooke, P. (2011). Constructing regional advantage: Platform policies based on related variety and differentiated knowledge bases. Regional studies, 45(7), 893-904.

Banco Nacional de Desenvolvimento Econômico e Social. Porte de Empresas. https://www.bndes.gov.br/wps/portal/site/home/financiamento/guia/porte-deempresa.

Barreto, C. P., Pantaleão, E. O., Silva, I. A. F., \& Hirata, S. (2019). Mapeamento das Empresas Filhas do Curso de Administração da Universidade Federal de Mato Grosso: Empreendedores Egressos, 1-388.

Associação Nacional de Entidades Promotoras de Empreendimentos Inovadores. (2016). Estudo de impacto econômico: segmento de incubadoras de empresas do Brasil. Brasília, DF.

Bekkers, R., \& Freitas, I. M. B. (2008). Analisando os canais de transferência de conhecimento entre as universidades e a indústria: em que medida os setores também importam? Política de pesquisa, 37 (10), 1837-1853.

Berni, J. C. A., Gomes, C. M., Perlin, A. P., Kneipp, J. M., \& Frizzo, K. (2015). Interação universidade-empresa para a inovação e a transferência de tecnologia. Revista Gestão Universitária na América Latina-GUAL, 258-277.

Bizzoto, C.E., Pires S.O. \& Chierighini, T. Incubadoras de empresas: conceituação, implantação e desafios. ANPROTEC, 2019.

Bogo, A. M., Schmitt, A. C., De Marco, R. G., \& Henning, E. (2015). Contribuições das empresas juniores para a formação acadêmica na visão dos alunos da UDESC Joinville. International Journal on Alive Engineering Education, 2(2), 61-70.

Brennan, M. C., \& McGowan, P. (2006). Academic entrepreneurship: An exploratory case study. International Journal of Entrepreneurial Behavior \& Research.

Bueno, G. W., Valentini, W. C., Veras, T. S. F., et. al (2020). Empresas filhas, Startups e Spin offs da UNESP. Relatório-de-empresas-filhas-da-UNESP-2020v.2.pdf.

Campos, E. B. D., Abbad, G. D. S., Ferreira, C. Z., \& Negreiros, J. L. X. M. D. (2014). Empresas juniores como espaços de apoio à formação profissional de estudantes universitários brasileiros. Revista Psicologia Organizações e Trabalho, 14(4), 452-463.

Criaco, G., Minola, T., Migliorini, P., \& Serarols-Tarrés, C. (2014). "To have and have not”: Founders' human capital and university start-up survival. The Journal of Technology Transfer, 39(4), 567-593.

Daniel, A. D. (2016). Fostering an entrepreneurial mindset by using a design thinking approach in entrepreneurship education. Industry and Higher Education, $30(3), 215-223$

Di Gregorio, D., \& Shane, S. (2003). Why do some universities generate more start-ups than others? Research Policy, 32(2), $209-227$.

Dornelas, J. (2013). Empreendedorismo na Prática: mitos verdades do empreendedor de sucesso. Elsevier Brasil.

Etzkowitz, H. (1983), “Entrepreneurial scientists and entrepreneurial universities in American academic science”, Minerva, $21,198-233$.

Etzkowitz, H. \& Klofsten, M. (2005). The innovating region: toward a theory of knowledge-based regional development. R\&D Management, 35(3), 243-255.

Etzkowitz, H., Zhou, C. (2017). Hélice Tríplice: inovação e empreendedorismo universidade-indústria-governo. Estudos avançados, 31 (90), 23-48.

Fayolle, A. (2018). Personal views on the future of entrepreneurship education. In A research agenda for entrepreneurship education. Edward Elgar Publishing.

Ferreira J. J. M., Fernandes C. I., \& Kraus S. (2019). Entrepreneurship research: mapping intellectual structures and research trends. Review of Managerial Science. 13, 181-205. 
Fernandes, D. R. (2004). Uma contribuição sobre a construção de indicadores e sua importância para a gestão empresarial. Revista da FAE, 7(1).

FORTEC. Pesquisa FORTEC de Inovação. (2020). https://fortec.org.br/wp-content/uploads/2021/01/Relatorio_anual_Ano_Base_2019.pdf.

Galán-Muros, V., van der Sijde, P., Groenewegen, P., \& Baaken, T. (2017). Nurture over nature: How do European universities support their collaboration with business? The Journal of Technology Transfer, 42(1), 184-205.

Ghio, N., Guerini, M., Lehmann, E. E., \& Rossi-Lamastra, C. (2015). The emergence of the knowledge spillover theory of entrepreneurship. Small Business Economics, 44(1), 1-18. doi:10.1007/s11187-014- 9588-y.

Guerrero, M., Cunningham, J. A., \& Urbano, D. (2015). Economic impact of entrepreneurial universities' activities: An exploratory study of the United Kingdom. Research Policy, 44(3), 748-764.

Hansen, E., Grosse-Dunker F., \& Reichwald. R. (2009). "Sustainability Innovation Cube - A Framework to Evaluate Sustainability-Oriented Innovations." International Journal of Innovation Management 13 (4): 683-713.

Hollveg, S. D. S., Zonatto, P. A. F., Dalla Nora, L. D., \& Bobsin, D. (2020). Modelos de gestão de incubadoras de empresas do estado do Rio Grande do Sul. Disciplinarum Scientia| Sociais Aplicadas, 16(1), 121-136.

Hurst, D. K. (1995), Crisis and Renewal: Meeting the Challenge of Organizational Change, Harvard Business Press.

Inova Unicamp. (2020). Relatório de Empresas-Filhas da Unicamp. Relatório-de-empresas-filhas-da-Unicamp-2020-v.2.pdf.

Ipiranga, A. S. R., Freitas, A. A. F. D., \& Paiva, T. A. (2010). O empreendedorismo acadêmico no contexto da interação universidade-empresa-governo. Cadernos Ebape. BR, 8(4), 676-693.

Kirby, D. A., \& Ibrahim, N. (2011). Entrepreneurship education and the creation of an enterprise culture: Provisional results from an experiment in Egypt. International Entrepreneurship and Management Journal, 7(2), 181-193.

Kirby, D. A., Guerrero, M., \& Urbano, D. (2011). Making universities more entrepreneurial: Development of a model. Canadian Journal of Administrative Sciences/Revue Canadienne des Sciences de l'Administration, 28(3), 302-316.

Kuckertz, A. (2013). Entrepreneurship education: Status quo and prospective developments. Journal of entrepreneurship education, $16,59$.

Lehmann, E. E. (2015). The role of universities in local and regional competitiveness. In D. B. Audretsch, A. N. Link, \& M. L. Walshok (Eds.), The Oxford handbook of local competitiveness (pp. 211-236). New York, NY: Oxford University Press.

Lehmann, E. E., \& Menter, M. (2016). University-industry collaboration and regional wealth. Journal of Technology Transfer, 41(6), $1284-1307$.

Lemos, P. (2012). Universidades e Ecossistemas de Empreendedorismo: Editora Unicamp.

Liñán, F. (2004). Intention-based models of entrepreneurship education. Piccolla Impresa/Small Business, 3(1), 11-35.

Link, A., Siegel, D., Wright, M., \& Ensley, M. (2006). An empirical analysis of the propensity of academics to engage in informal university technology transfer. Working Paper in Economics, 0610. Rensselaer Polytechnic Institute.

Matlay, H., Pittaway, L., \& Edwards, C. (2012). Assessment: examining practice in entrepreneurship education. Education+ Training.

Meoli, M., Paleari, S., \& Vismara, S. (2013). Completing the technology transfer process: M\&As of science-based IPOs. Small Business Economics, 40(2), $227-248$.

Mori, M. R., Barbosa, V. R. S., Nania, R. M., \& Rezende, M. (2017). Inovação em rede: boas práticas de gestão em Nits. In Inovação em rede: boas práticas de gestão em Nits (pp. 350-350).

Mustar, P., Wright, M., \& Clarysse, B. (2008). University spin-off firms: lessons from ten years of experience in Europe. Science and Public Policy, 35(2), 6780 .

Noveli, M. \& Segatto, A. P. (2012). Processo De Cooperação Universidade-Empresa Para A Inovação Tecnológica Em Um Parque Tecnológico: Evidências Empíricas E Proposição De Um Modelo Conceitual. RAI Revista De Administração E Inovação, v. 9, n. 1, p. 81-10.

Organisation for Economic Co-operation and Development. (2018). The future of education and skills: Education 2030. Recuperado em 03 abril, 2021, de: https://www.oecd.org/education/2030/E2030\%20Position\%20Paper\%20(05.04.2018).pdf.

Paranhos, J., Cataldo, B., \& Pinto, A. C. D. A. (2018). Criação, institucionalização e funcionamento dos núcleos de inovação tecnológica no Brasil: Características e desafios. REAd. Revista Eletrônica de Administração (Porto Alegre), 24(2), 253-280.

Pavani, C. (2015). Spin offs universitárias de sucesso: um estudo multicasos de empresas originárias da Escola Politécnica da USP e da COPPE da UFRJ (Doctoral dissertation, Universidade de São Paulo).

Peng, X. (2006). University spin-offs: Opportunity or challenge? Nature materials, 5(12), 923-925.

Rasmussen, E., \& Wright, M. (2015). How can universities facilitate academic spin-offs? An entrepreneurial competency perspective. The Journal of Technology Transfer, 40(5), 782-799.

Ribeiro A. T. V. B., Plonski G. A. Educação empreendedora: o que dizem os artigos mais relevantes? proposição de uma revisão de literatura e panorama de pesquisa. Rev. Empreendedorismo Gest. Pequenas Empres. 9(1), 10-41, 2020. 
Research, Society and Development, v. 11, n. 3, e45311326661, 2022

(CC BY 4.0) | ISSN 2525-3409 | DOI: http://dx.doi.org/10.33448/rsd-v11i3.26661

Rother E.T. (2007). Revisão sistemática X revisão narrativa. Acta paul. Enferm ; 20(2):v-vi.

Roberts, E. B., Murray, F., \& Kim, J. D. (2019). Entrepreneurship and innovation at MIT: continuing global growth and impact. Cambridge, MA: Martin Trust Center for MIT Entrepreneurship.

Schaltegger, S., \&. Wagner M. (2011). "Sustainable Entrepreneurship and Sustainability Innovation: Categories and Interactions." Business Strategy and the Environment 20 (4): 222-237.

Serviço Brasileiro de Apoio às Micro e Pequenas Empresas. (2016) Empreendedorismo nas Universidades brasileiras. Recuperado em 01 novembro, 2019 , de https://www.sebrae.com.br/Sebrae/Portal\%20Sebrae/Anexos/Relatorio\%20Endeavor\%20impressao.pdf.

Siegel, D. S., \& Wright, M. (2015). Academic entrepreneurship: time for a rethink? British Journal of Management, 26(4), 582-595.

Siegel, D. S., \& Wright, M. (2015). University technology transfer offices, licensing, and start-ups. In A. Link, D. S. Siegel, \& M. Wright (Eds.), Chicago handbook of university technology transfer and academic entrepreneurship (Vol. Forthcoming). Chicago, IL: University of Chicago Press.

SISU - Sistema de Seleção Unificada. Recuperado em 25 agosto, 2021 de: https://sisu.mec.gov.br/\#/vagas?categoria=instituicao\&id=107\#target .

Skute, I. (2019). Opening the black box of academic entrepreneurship: a bibliometric analysis. Scientometrics, 120(1), 237-265.

Teixeira, L.A.D.C. (2018). Como os núcleos de inovação tecnológica dos institutos públicos de pesquisa podem contribuir para os resultados de inovação do Estado de São Paulo: um estudo de caso dos institutos da administração direta do governo do Estado (Doctoral dissertation, Universidade de São Paulo).

Tidd, J., Bessant, J. \& Pavitt, K. (2005), Managing Innovation, Wiley, Chichester.

Torkomian, A. L. V. (2009). Panorama dos núcleos de inovação tecnológica no Brasil. Transferência de tecnologia. Campinas: Komedi, 21-37.

Wadhwani, R. D., Galvez-Behar, G., Mercelis, J., \& Guagnini, A. (2017). Academic Entrepreneurship and Institutional Change in Historical Perspective. Management \& Organizational History, 12(3), 175-198.

Wright, M., Clarysse, B., Mustar, P., \& Lockett, A. (Eds.). (2007). Academic entrepreneurship in Europe. Cheltenham: Edward Elgar.

Wood, M. S. A process model of academic entrepreneurship. (2011). Business Horizons 54, 153-161. 